\title{
Administração de recursos humanos no setor público
}

\author{
Human resources management in the public sector \\ Gestión de recursos humanos en el sector público
}

Recebido: 18/01/2022 | Revisado: 23/01/2022 | Aceito: 01/02/2022 | Publicado: 03/02/2022

\author{
Viviane Rodrigues Sales dos Santos \\ ORCID: https://orcid.org/0000-0001-7564-3076 \\ Centro Universitário Augusto Motta, Brasil \\ E-mail: vivianersales@hotmail.com \\ Alessandra Conceição Santos Corrêa \\ ORCID: https://orcid.org/0000-0002-5337-5602 \\ Centro Universitário Internacional Uninter, Brasil \\ E-mail: ale.laeber@gmail.com
}

\begin{abstract}
Resumo
Este trabalho tem como proposta entender o funcionamento da Administração de Recursos Humanos no Setor Público. A metodologia utilizada foi a pesquisa bibliográfica. A administração pública tem por objetivo principal atender ao interesse público e às necessidades sociais. Para o cumprimento da sua função administrativa, o Estado possuí certas prerrogativas the asseguradas por lei; contudo, tais prerrogativas precisam ser utilizadas no cumprimento das ações que foram propostas em sua criação. $\mathrm{Na}$ administração pública, administrar vai além de executar serviços públicos, mas direcionar e gerenciar buscando o bem e a satisfação da sociedade. A literatura a respeito de gestão de pessoas na área privada é bastante ampla, no entanto, aquela específica para a área pública é escassa e dispersa. Por um longo período, a gestão de pessoas na área pública tinha como foco principal a realização de atividade operacional, não havendo instruções claras sobre as diretrizes que regiam os recursos humanos. A falta de capacitação e de participação da equipe se perderam devido à falta de objetivos, pois elevado é o nível de comprometimento que exige a mudança, onde muitas das vezes não são vistas como melhoria, mas perca de tempo.
\end{abstract}

Palavras-chave: Administração pública; Estratégia; Recursos humanos.

\begin{abstract}
This work aims to understand the functioning of Human Resources Management in the Public Sector. The methodology used was bibliographic research. Public administration's main objective is to meet the public interest and social needs. For the fulfillment of its administrative function, the State has certain prerogatives guaranteed by law; however, such prerogatives need to be used in the fulfillment of the actions that were proposed in its creation. In public administration, managing goes beyond performing public services, but directing and managing seeking the good and satisfaction of society. The literature on people management in the private area is quite extensive, however, that specific to the public area is scarce and dispersed. For a long time, people management in the public area had as its main focus the performance of operational activities, with no clear instructions on the guidelines that governed human resources. The lack of training and team participation were lost due to the lack of objectives, as the level of commitment that requires change is high, where they are often not seen as improvement, but a waste of time.
\end{abstract}

Keywords: Public administration; Strategy; Human Resources.

\section{Resumen}

Este trabajo tiene como objetivo comprender el funcionamiento de la Gestión de Recursos Humanos en el Sector Público. La metodología utilizada fue la investigación bibliográfica. La administración pública tiene como principal objetivo satisfacer el interés público y las necesidades sociales. Para el cumplimiento de su función administrativa, el Estado cuenta con ciertas prerrogativas garantizadas por la ley; sin embargo, tales prerrogativas deben ser utilizadas en el cumplimiento de las acciones que se propusieron en su creación. En la administración pública, dirigir va más allá de la prestación de servicios públicos, sino de dirigir y gestionar buscando el bien y la satisfacción de la sociedad. La literatura sobre gestión de personas en el ámbito privado es bastante extensa, sin embargo, la específica para el ámbito público es escasa y dispersa. Durante mucho tiempo, la gestión de personas en el área pública se centró principalmente en la realización de actividades operativas, sin instrucciones claras sobre los lineamientos que regían los recursos humanos. La falta de formación y participación del equipo se perdió por la falta de objetivos, porque el nivel de compromiso que requiere el cambio es alto, donde muchas veces no se ven como mejora, sino como una pérdida de tiempo.

Palabras clave: Administración pública; Estrategia; Recursos humanos. 


\section{Introdução}

O controle das ações realizadas e das pessoas envolvidas no propósito dos recursos humanos na Gestão Pública, tanto nas atividades internas como externas (atendimento ao público), é de suma importância para estimar o desempenho, e quando julgar necessário, realizar as melhorias adequadas a cada situação. Segundo Cruz (2018), a gestão estratégica de pessoas, tem recebido mais atenção das empresas nesses últimos anos, isso ocorre pelo fato dessa mudança trazer a pessoa certa para o lugar certo dentro de uma organização. Andrade (2016), defende a ideia de que antes das empresas irem em direção aos seus objetivos, atividades para qual foram criadas, elas precisam verificar se possuem todos os recursos necessários para tal. Isso quer dizer que além da organização ou implantação do sistema de gestão de recursos humanos no serviço público faz-se necessário a adoção de alguns mecanismos, procedimentos ou ferramentas para melhorar a eficiência do sistema através da descrição de cargos, procedimentos administrativos, procedimentos operacionais, treinamento e desenvolvimento do capital humano, avaliação de desempenho e competência, investimentos em tecnologia, vontade política, profissionalização ou capacitação dos servidores públicos, estrutura de servidores de provimento efetivo, estrutura física do sistema de controle interno e consequentemente melhorará a eficiência administrativa. Muito tem se ouvido falar na morosidade, na burocracia e nos erros ou irregularidades que se cometem nos procedimentos ou rotinas da administração pública, em função da má gestão dos recursos humanos nos órgãos públicos, a tal ponto de comprometer o atendimento das necessidades da sociedade. Portanto, com esse estudo, levando em consideração o problema apontado, busca-se resposta para entender como funciona a gestão de pessoal, recursos humanos, no serviço público.

\section{Metodologia}

O presente artigo assumiu o a forma de pesquisa exploratória com abordagem qualitativa que têm objetivo por objetivo familiarizar-se com o fenômeno ou obter uma nova percepção dele e descobrir novas ideia. (Cervo, 2007.). Conforme Mascarenhas (2012), usamos a pesquisa qualitativa quando queremos escrever nosso objeto de estudo com mais profundidade. Após pesquisas em livros e artigos eletrônicos este artigo também assumiu a forma de pesquisa de coleta de dados bibliográfica, nas quais fundamentaram a tese proposta.

\section{Resultados}

Os princípios norteadores da Administração Pública constam do artigo, 37 da Constituição da República Federativa do Brasil (1988), de qual exegeticamente descrevem que, "a administração pública direta e indireta de qualquer dos Poderes da União, dos Estados e dos municípios obedecerá aos princípios de legalidade, impessoalidade, moralidade, publicidade e eficiência." Frizzo \& Paranhos (2021), afirmam que esses princípios são os eixos estruturantes responsáveis por conferir identidade ao sistema normativo da gestão pública. Nesse sentido, no que se refere ao princípio da legalidade, entende-se que o administrador não pode agir, nem deixar de agir, senão de acordo com a lei na forma determinada (está inserto neste princípio o interesse público e sua prevalência sobre o individual, respeitadas as garantias constitucionais).

Ao destrinchar os objetivos de cada um dos princípios estabelecidos, pode-se afirmar que a publicidade tem o propósito de tornar público as suas execuções no cumprimento dos serviços prestados à sociedade, salvo os casos relacionados a processos em segredo de justiça, investigações e segurança nacional. Quanto a eficiência, está relacionada ao método de realização das atividades; a eficácia mensura se o objetivo proposto ao realizar uma tarefa foi alcançado ou não; e a efetividade diz respeito a qualidade do resultado desejado. E para que a Administração Pública consiga cumprir os seus princípios e dar eficiência, eficácia e efetividade na execução de necessidades públicas para a coletividade há necessidade de ter mecanismos 
de controle interno ou órgão de controle interno. É importante ressaltar que tais controles só serão possíveis se houver uma boa gestão dos recursos que serão os pilares desse processo, ou seja, os recursos humanos.

\subsection{A importância da gestão de recursos humanos na administração pública}

Em 1883, segundo Santos (2006) foi nos Estados Unidos, onde surgiu a primeira menção a função de recursos humanos, a qual era denominada de administração de pessoal, com a Criação da Comissão de Serviço Público. Nesse período, a organização do serviço de pessoal foi padronizada, contando com as seguintes seções apenas: administrativa, de controle, financeira e de assistência social. Para Souza (2018), com o passar do tempo e principalmente com a globalização, onde há tantas informações disponíveis, a qualidade dos serviços são cada vez mais cobradas pelos usuário, pensando nisso é importante ressaltar que são as pessoas que prestam os serviços solicitados e para que haja um bom atendimento é essencial que tais pessoas estejam motivadas.

$\mathrm{Na}$ área pública começou a pensar na necessidade de valorização e capacitação do servidor, a uma melhoria na vida e do trabalho na organização. Ao se referir à gestão de pessoas no setor, Bergue (2007, p. 18) a define como: “[...] esforço orientado para o desenvolvimento de pessoas públicas, a manutenção de pessoas públicas nas organizações públicas, em conformidade com os ditames constitucionais e legais, observadas as necessidades e condições do ambiente em que se inserem." Os resultados obtidos na gestão de recursos humanos dependem, em grande parte, do comportamento das pessoas do trabalho. Se esse comportamento for de forma adequada aos objetivos organizacionais, a probabilidade de sucesso é maior. A tendência atual é conscientizar cada pessoa no sentido de que ela seja o elemento de diagnóstico e solução de problemas para obter uma melhoria contínua de seu trabalho na organização. Segundo este mesmo autor, Bergue (2008, p. 18) “[...] uma área de gestão de pessoas não deve ser conhecida pelo que é, mas sim pelos resultados que entrega e aumenta a competitividade da empresa e contribuição para criar valor para os clientes, acionista e empregado".

A gestão de pessoas, que ainda hoje atua mais no comportamento humano; precisar descobrir novas formas de atuação da organização para obter resultados mais eficazes, além de lidar com a transformação que ocorre com cada novo gestor. É de grande importância que o administrador seja um gestor de ampla visão, capaz de buscar novas alternativas e disposto a mudanças. Vale ressaltar que as organizações dependem das pessoas para sua subsistência, pois as organizações jamais existiriam sem elas.

Ao se referir ao Recurso Humano (RH), Dutra (2009, p. 40) afirma que "[...] a estratégia do RH pode ser definida como uma definição de políticas e diretrizes em relação aos recursos de gestão humana para aumentar a habilidade dos servidores - e, por consequência, do próprio órgão público - para realizar seu trabalho de modo a alcançar seus objetivos." Sabe-se da importância de uma administração eficiente, com planejamento em todas as suas áreas. Na gestão de pessoas não é diferente, precisa ser elaborada com a sua população, pois é ela responsável em analisar as qualidades e habilidades de cada servidor, para encaminhá-lo ao setor não melhor suas atribuições, gerando um atendimento de excelência à população.

Segundo Dutra (2009), a gestão estratégica do RH na organização pública tem início com uma vasta discussão sobre o papel da sociedade, pois são os fatores econômicos que definirão os limites orçamentários que serão enfrentadas, além das competências e atribuições do quadro pessoal. Quando se fala em gestão de pessoas, compare-se as formas de gestão no serviço público com aquelas do serviço privado. O procedimento de gestão de pessoas em um órgão público ou privado é bem semelhante, o que muda é a função social, a cultura organizacional, a legislação específica do ramo de atividade, as normas internas, as regras e as tradições. 


\subsection{Gestão de recursos humanos na área pública}

Para Tachizawa et al. (2001), gestão de pessoas pode ser definida como um processo descentralizado de gestão de pessoas responsável, cada qual em sua área, pelas atividades-fim e atividades-meio das organizações. A gestão de recursos humanos deve ser aperfeiçoada a partir dos cidadãos, porque é da perspectiva da realização dos propósitos das organizações públicas que a gestão de pessoas ser precisa. Quando esse conjunto de trabalho está direcionado às pessoas, temos o conceito de gestão de pessoas, que segundo Dutra $(2009$, p. 42) é: “[...] um conjunto de políticas e práticas que permite uma conciliação de expectativas entre a organização e as pessoas para que ambas possam realizá-las ao longo do tempo.” De acordo com Santos (2009, p. 19), “[...] A administração de recursos humanos prevê o ser humano como um recurso na administração e cuida de sua instrumentalização: seleção, contratação, treinamento, missão etc. Ressaltando que "[...] já a gestão de pessoas, denota o caráter subjetivo do indivíduo dentro da organização, não o mostra apenas como parte do processo, mas como pessoa: um ser complexo, mutável, criativo e fantástico.”

Saiba que o planejamento é de grande importância para o sucesso da organização, principalmente quando esta for pública. Então, conforme Bergue (2007), o planejamento estratégico de recursos humanos deve ser parte integrante do planejamento estratégico da organização, devendo a gestão constar: valores institucionais relativos à nele de pessoas; cenários e futuro de atuação do órgão ou atual entre público; e diretrizes gerais de políticas de dimensionamento de pessoas; treinamento e desenvolvimento destas; Remuneração e incentivos, atuação e integração social.

Contudo, de modo geral as administrações públicas não valorizam a área de recursos humanos, enquanto outras empresas do setor privado estão tratando esta área como sendo estratégica para a organização em busca de seus resultados. $\mathrm{O}$ setor público trata-o como um setor que contrata e exonera pessoas, esquecendo que ele deve buscar a qualificação dos servidores, além de servir como elo entre estes e a administração, podendo chegá-lo a um diferencial competitivo.

\subsection{Gestão de Recursos Humanos por Competência na Área Pública}

O contexto das diretrizes de gestão de recursos humanos na administração pública do país é marcado por uma série adversidades quanto à estruturação dos seus principais sistemas. Além de políticas de gestão, é necessária a competência profissional, resultado da aplicação no trabalho de conhecimento, habilidade e atitude, que representam os três recursos ou dimensões da competência (Pires, 2005). Segundo Costa et al. (2020), esse conjunto de capacidades estão alinhadas com a conceituação de agregação de valor e são expostas através dos comportamentos que o servidor tem no cotidiano de seu trabalho.

Segundo Pires (2005), para vários estudiosos, o conhecimento corresponde a uma série de informações adquiridas e estruturadas; refere-se ao saber que a pessoa acumulou ao longo da vida. A habilidade está relacionada ao saber como fazer algo, à capacidade de fazer uso do conhecimento; já a atitude se relaciona a um sentimento, uma emoção, à aceitação ou rejeição da pessoa em relação aos outros, a objetos ou situações, ou seja, querer fazer. Muitas organizações têm adotado o modelo de gestão por competências, visando a orientar seus esforços para planejar, captar, desenvolver e avaliar os níveis da organização. É sabido que o recrutamento e a seleção são muito importantes no modelo de gestão de pessoas, pois a falta de seleção adequada certamente gerará custos para a organização. Pires (2005), ainda afirma que ao efetuar-se o recrutamento e a seleção, é preciso definir os resultados que se pretende alcançar com os serviços prestados e criar uma equipe permanente de seleção, buscando não avaliar somente o conhecimento técnico, mas mensurar também as habilidades, atitudes, perfil, personalidade e valores, considerando as características do cargo ou posto que seja ocupado. A gestão de pessoas deve se atentar mais às inconstâncias comportamentais como personalidade, valores das pessoas e interesses, pois tais questões no setor público são recentes, necessitando da realização de vários estudos para uma compreensão maior do tema. 
O desenvolvimento de recursos humanos é um processo que além da transmissão de conhecimentos, da criação de atitudes e dos comportamentos voltados ao desenvolvimento dos próprios indivíduos ou grupo, busca atender aos objetivos institucionais e estratégicos, possibilitando flexibilidade nas mudanças, além de estimular um ambiente de desenvolvimento e trabalho participativo. Segundo Bergue (2007, p. 169): “[...] a avaliação de desempenho na gestão de pessoas pode enfocar: a) as pessoas no exercício de suas atividades; b) os processos inerentes à área de gestão de pessoas." As pessoas precisam ser avaliadas na atividade e no local em que estão desenvolvendo suas tarefas, devendo ser adequadas em setores nos quais suas habilidades melhores contribuem na organização e no setor público, e isso deve ser encarado com seriedade, pois o produto oferecido é o bem coletivo. Nesse sentido, uma gestão de pessoas eficiente é aquela em que as pessoas utilizam todo seu potencial, tanto em habilidade e competência quanto em atividade e serviço.

\section{Discussão}

Como resultado da constituição de 1988, houve muitas mudanças no setor público. Mudanças essas que têm o objetivo de tornar as contratações junto ao setor público, mais transparentes e profissionais, minimizando, diminuindo a incidência das perseguições políticas e nepotismo. Silva (2019), afirma que nepotismo é o favorecimento de parentes, em razão da posição ocupada na Administração Pública, de maneira a ofender a regra da predominância do interesse público sobre o privado. Com o objetivo de eliminar tais práticas, neste período, foi apresentada a toda cúpula da administração pública o concurso público, também a estabilidade no emprego público foi introduzida na administração direta, portanto, as contratações na área pública passam a ser realizadas através de concursos, um meio mais transparente, aberto, mais justo e com critérios e princípios técnicos. Referente a essas mudanças, Lemos (2010), afirma que se por um lado estes objetivos foram atingidos, por outro lado criou-se um mastodonte, um excesso de servidores em muitas áreas e baixa rotatividade da força de trabalho. Segundo o mesmo autor, é improdutiva a troca frequente de funcionários, seja pelos custos trabalhistas, seja pelo tempo e recurso investidos na integração e aprendizado do contratado, no entanto, também é ruim não poder trocar nenhum funcionário quando necessário.

Marzzoni et al. (2020) afirma que com um nível de conhecimento, grau de instrução, elevado se torna mais fácil para um gestor gerenciar pessoas, além de auxiliar na tomada de decisão. Por estas razões é que a administração de recursos humanos necessita implantar um sistema de incentivos para o profissional, pois é evidente a falta de uma política de formação, capacitação permanente e remuneração coerente com o exercício da função pública. Ao se referir aos recursos humanos, afirma que: "Desenvolver recursos humanos não significa uma ação periódica de aprimorar o desempenho do exercício de certa função, mas um processo individual, grupal, organizacional permanente de autocrítica, descoberta a atualização do potencial de criatividade e realização humana em seus diversos níveis de manifestação.” (Mattos, 1982).

O quadro de servidores deve ser composto por funcionários que possuam conhecimentos técnicos a respeito de matérias específicas, além de um conjunto de habilidades e atitudes compatíveis com as atribuições que exercerão. Com base nisso, Pires (2005, p. 23) ressalta: “[...] tendo em vista as peculiaridades dos processos seletivos das organizações públicas, conduzidos com o objetivo de elevar seus níveis de efetividade, é mister definir metodologias que permitam a elaboração de estratégias de recrutamento eficazes." É preciso que as organizações busquem, além da seleção por meio de provas e comprovação de títulos, outras formas de avaliação, procurando identificar as competências interpessoais, estratégicas e gerenciais de cada candidato. Essa nova maneira de avaliar objetiva contar com servidores aptos a desempenhar suas funções, além da motivação em suas carreiras (Pires, 2005). O desafio da gestão de pessoas é proporcionar à organização pessoas com características superiores e experientes, bem capacitadas, motivadas e leais, contribuindo com uma cultura de alto desempenho, além de se manter austero e atuar disciplinadamente conforme as diretrizes definidas. 
Historicamente, a gestão de pessoas surgiu na organização em razão da demanda de atividades para cumprimento das leis trabalhistas e para adotar medidas de controle, principalmente disciplinares. As organizações da administração pública possuem natureza permanente, no entanto, estão submetidas às contínuas transformações devido às mudanças de governo. Por isso, o grande desafio é manter a estabilidade da organização e conviver com a mudança. Isso implica desenvolver estratégias de recursos humanos com maior flexibilidade, possibilitando constituir organizações públicas coerentes e permanentes. Os profissionais que atuam com a gestão de pessoas, precisam adquirir ainda novas competências conceituais, técnicas e humanas, sistematizadas em um novo perfil, de acordo com o qual sejam capazes de atender tanto os usuários internos quanto os externos à organização. Em uma perspectiva de evolução, podemos tratar a gestão de pessoas em três estágios: a) a administração de pessoal - rotinas de geração de folha de pagamento, manutenção de registros, assentamentos funcionais e controle dos servidores; b) administração de recursos humanos - sensível avanço quanto ao elemento humano e nos processos de trabalho, análise sistêmica da organização e destaque no ambiente laboral; c) administração de pessoas - organizações voltadas às pessoas como seu mais valioso componente de capital, recurso capaz de gerar riquezas. (Gemelli \& Filippim, 2010).

Percebe-se que a gestão de pessoas no setor público se encontra no estágio de administração de pessoal, exercendo muitas vezes atividades meramente burocráticas, sendo necessário evoluir para novos estágios, buscando integração entre a organização e seus servidores. Sabe-se que as políticas de recursos humanos passaram por dificuldades quanto às tentativas de planejar, captar, desenvolver e avaliar a organização.

\section{Considerações Finais}

A gestão de recursos humanos no serviço público em qualquer esfera de governo visa prestar serviços tanto internamente como externamente e auxilia o gestor de recursos humanos na correta aplicação dos recursos, a fim de beneficiar os cidadãos através de bens e serviços públicos. Arruda (2018), afirma que capacidade, representa a eficiência com o que o serviço é oferecido e prestado à sociedade, a maneira como empresa pública gere os recursos que possui para entregar serviços; e desta forma as capacidades são representadas como a habilidade de adaptação e transformação para oferecer um serviço à sociedade. Com a aplicação dessa capacidade a gestão de recursos humanos no serviço público fica fortalecida, estando menos vulnerável a erros, fraudes e desperdícios.

O sistema de gestão de recursos humanos deve agir de modo preventivo e na ocorrência de eventuais erros ou irregularidades, introduzir mecanismos ou procedimentos para que não haja repetição. As ações de gestão de recursos humanos de um órgão público não devem ser única e exclusivamente do gestor, mas sim de todos os órgãos, departamentos, enfim de todas as pessoas que ali trabalham coordenadas por uma unidade central ou por unidades setoriais de gestão ou muitas vezes por um assessor, consultor de Gestão, quando a administração municipal for menor de porte.

Para se manter a eficiência do sistema de gestão pública de recursos humanos, o gestor deve implantar o sistema de controle de gestão para satisfazer a lei, sendo necessário adotar alguns procedimentos, ferramentas ou mecanismos para melhor eficiência do sistema de gestão, como prevenção de evitar erros, fraudes ou desperdícios, tais como: vontade política, estrutura de servidores de provimento efetivo, estrutura física, integridade e competência, acompanhamento dos controles, segregação de funções, rodízio de funções, profissionalização no setor público, autonomia da unidade de gestão e seus integrantes. Além disso, se a unidade de gestão de recursos humanos possuir uma equipe multidisciplinar, maior será a eficiência desta por consequência da gestão pública. Essa autonomia funcional e técnica geralmente se encontram onde existe maior estrutura administrativa.

Outro aspecto importante quando se fala na profissionalização ou capacitação dos servidores de modo geral, é a capacitação por meio de cursos presenciais, à distância. Isso pode contribuir na sua melhor eficiência e funcionamento do 
sistema de Gestão, pois o gestor detém os recursos humanos e também é dele que partem as principais decisões na organização do sistema de gestão.

A responsabilidade do gestor de recursos humanos no serviço público ou qualquer membro de sua equipe é passível de responder perante atitudes ou omissões dentro da gestão pública. Nesta atividade, é preciso que o gestor esteja atento para que o custo do procedimento de Gestão não seja maior que o benefício, a não ser em alguns procedimentos estritamente necessários e estratégicos. Isso não significa que a gestão não precisa ser feita, mas que esta seja menos rigorosa. Mesmo com todos esses procedimentos, não quer dizer que não possam existir erros, falhas ou irregularidades intencionais ou não, pois o ser humano é passível de falhas e nenhum sistema é perfeito.

Sendo assim, sugere-se que haja mais pesquisas voltados para a capacitação do servidor público, analisando seu perfil profissional, habilidade e motivações para tal serviço. Outro objeto de pesquisa importante sobre o tema é a gestão estratégica de pessoas, como vimos, em empresas privadas esse conceito é bem amplo e mais estruturado, enquanto a administração pública, até o presente momento, pouco tem se envolvido nessa área.

\section{Referências}

Andrade, A. R. (2016) Planejamento Estratégico: formulação, implementação e controle. (2 ed.) Atlas.

Arruda, T. J. M. (2018). Inteligência Emocional e Capacidade Dinâmica: Uma Abordagem Voltada para a Melhoria da Gestão Pública. Revista Científica Multidisciplinar Núcleo do Conhecimento. https://www.nucleodoconhecimento.com.br/administracao/inteligencia-emocional\#23-CAPACIDADESDINAMICAS-NA-GESTAO-PUBLICA

Bergue, S. T. (2007) Gestão de Pessoas em Organizações Públicas. (2. ed.), Educs.

Brasil. (1988). Constituição: República Federativa do Brasil de 1988. Brasília, DF: Senado Federal.

Cervo, A. L. (2007). Metodologia científica. (6 ed.). Pearson.

Costa, A. C. A; Barros, J. G. M; Oliveira, A. C. L; Sampaio, A. S. \& Silva, J. W. J. (2020). Gestão por competência em recursos humanos. https://rsdjournal.org/index.php/rsd/article/view/5383

Cruz, A. C. dos S. (2018). Educação e a Gestão Pública: Liderança, Processo Decisório e Gestão de RH. Revista Científica Multidisciplinar Núcleo do Conhecimento. https://www.nucleodoconhecimento.com.br/educacao/educacao-e-a-gestao-publica

Dutra, A. (2009). Gestão de pessoas na área pública. Curso de Especialização em Administração Pública. SC/Joaçaba: Unoesc.

Frizzo, H. \& Paranhos, G. (2021). A efetividade dos princípios da administração pública no cenário atual. https://www.jota.info/opiniao-eanalise/artigos/principios-administracao-publica 06082021\#: :text=J\%C3\%A1\%20a\%20Lei\%20Federal\%20n\%C2\%BA,do\%20interesse\%20p\%C3\%-BA bli co $\% 2$ C 20 da\%20probidade

Gemelli, I.M. P. \& Filippim, E. S. (2011). Gestão de pessoas na administração pública: o desafio dos municípios. RACE - Revista de Administração, Contabilidade e Economia, 9(1-2), 153-180. https://portalperiodicos.unoesc.edu.br/race/article/view/375

Lemos, M. L. (2011). Gestão de pessoas na Administração Pública: recursos humanos na administração pública. https://www.crasp.gov.br/centro/conteudo/old/uploads/22_07_2011_Gestao_de_pessoas_na_Administracao_Publica.pdf.

Martins, R. C. (2012). Gestão de Pessoas em organizações públicas. https://docplayer.com.br/7297115-Regina-copello-martins-gestao-de-pessoas-em-umaorganizacao-publica-uma-proposta-de-melhoria.html.

Marzzoni, D \& Rodrigues, L. (2020). Identificação do perfil dos profissionais contábeis dos escritórios do município de Marabá, Estado do Pará, Brasil. Research, Society and Development, 9 (7), e185973938. doi:http://dx.doi.org/10.33448/rsd-v9i7.3938

Mascarenhas, S. (2012). Metodologia Científica. São Paulo: Person Education do Brasil.

Mattos, R. A. (1982). O desenvolvimento de recursos humanos na Administração Pública. Rio de Janeiro: Revista de Administração Pública.

Pires, Alexandre Kalil et al. (2005). Gestão por competências em organizações de governo. https://esmec.tjce.jus.br/wp-content/uploads/2013/06/8-gestao-porcompetencia.pdf

Santos, C. S. (2006). Introdução à gestão pública. Saraiva.

Santos, D. R. C. (2009) A gestão de pessoas no ministério dos transportes. Monografia. Faculdade Cenecista de Brasília. Brasília.

Silva, D. E G. (2019). O Nepotismo à Luz Dos Cargos Políticos da Administração Pública: Uma Abordagem Segundo a Súmula Vinculante Número 13 do Supremo Tribunal Federal. https://ambitojuridico.com.br/cadernos/direito-administrativo/o-nepotismo-a-luz-dos-cargos-politicos-da-administracao-publicauma-abordagem-segundo-a-sumula-vinculante-numero-13-do-supremo-tribunal-federal/\#_edn1

Souza, E. R. L. (2018) - Gestão de pessoas no setor público. http://dspace.nead.ufsj.edu.br/trabalhospublicos/bitstream/handle/123456789/178/TCC\%20$\%$ 20Elaine $\% 20$ Regina $\% 20$ Lopes $\% 20$ Souza $\% 20 \% 28 \mathrm{P} \%$ C3\%B3s\%20Banca\%29.pdf?sequence=1\&isAllowed=y 